\title{
Chronic Non-Communicable Diseases in College Students in the Brazilian Western Amazon Region
}

\author{
Lucas Felipe de Macedo', Tatiane Dalamaria1,2, Margarida de Aquino Cunha1,2, \\ Luiz Carlos de Abreu ${ }^{3}$, Orivaldo Florencio de Souza ${ }^{1,2 *}$ \\ ${ }^{1}$ Center for Health Sciences and Sports, Federal University of Acre, Rio Branco, Brazil \\ ${ }^{2}$ Federal University of Acre, Rio Branco, Brazil \\ ${ }^{3}$ Faculty of Medicine of ABC, Santo André, Brazil \\ Email: ${ }^{*}$ orivaldofs.ufac@gmail.com
}

Received 14 September 2014; revised 31 October 2014; accepted 17 November 2014

Copyright (C) 2014 by authors and Scientific Research Publishing Inc.

This work is licensed under the Creative Commons Attribution International License (CC BY). http://creativecommons.org/licenses/by/4.0/

(c) (i) Open Access

\section{Abstract}

The objective of this study was to analyze the prevalence of chronic non-communicable diseases (CNCDs) and associated lifestyle factors in college students in Rio Branco, Acre, Brazilian Western Amazon region. A cross-sectional study was conducted in 874 undergraduate students from a public university. The general prevalence of CNCDs was 15.6\%. After adjusting for sex and age, the CNCD-associated lifestyle factors included the following: sedentary during leisure time (prevalence ratio (PR): 1.67; 95\% confidence interval (CI): 1.12 - 2.48), sedentary in locomotion by walking (PR: 1.34; 95\% CI: 1.00 - 1.79), current smoker (PR: 1.66; 95\% CI: 1.07 - 2.58), unsatisfactory self-rated health status (PR: 2.31; 95\% CI: 1.84 - 2.88), overweight (PR: 1.67; 95\% CI: 1.14 - 2.46) and obese (PR: 3.30; 95\% CI: 2.18 - 5.01). The high prevalence of CNCDs identified in this group of college students highlights the need for swift action to promote healthy lifestyles among youth.

\section{Keywords}

Chronic Disease, Epidemiological Factors, Students, Cross-Sectional Studies

\section{Introduction}

Chronic non-communicable diseases (CNCDs), being a global public health concern [1]-[3], are characterized by long duration, slow progression and non-infectious. The main CNCDs are cardiovascular diseases, diabetes,

${ }^{*}$ Corresponding author.

How to cite this paper: de Macedo, L.F., Dalamaria, T., de Aquino Cunha, M., de Abreu, L.C. and de Souza, O.F. (2014) Chronic Non-Communicable Diseases in College Students in the Brazilian Western Amazon Region. Health, 6, $2749-2755$. 
cancers and chronic respiratory diseases. Currently, alcohol abuse, obesity, smoking, physical inactivity and unhealthy diet are the major risk factors contributing to CNCDs [4].

Furthermore, these diseases are associated with poverty and socioeconomic inequality [5]. In this context, a high prevalence of CDCNs occurs in developing countries, such as Brazil (32.6\%), [6] South Africa (50.7\%) [7] and Vietnam (33.4\%) [8]. In Brazil, 72\% of the deaths recorded in 2007 were associated with CNCDs [1]. Regional disparities were identified in Brazil; the southern and southeastern regions had a lower CNCDs prevalence than the northern and northeastern regions did, which were the poorest regions in Brazil [1].

Despite the prevalence of CNCDs has been published for Brazilians citizens, the burden of CNCDs in specific groups should be investigated [9]. Specifically in the education level, the increase in the number of years of schooling is inversely associated with decreased prevalence of CDCNs [6] [10].

Lifestyle changes have been observed in students entering university [11]. These lifestyle changes, which are thought to be related to adaptation to the university setting and new social networks, lead to greater exposure to CNCDs-related risk factors. For incoming students who are already affected by a CNCD, failure to maintain healthy behaviors exposes them to aggravation of their CNCDs.

In the Brazilian Western Amazon, dissemination of scientific information on the prevalence of CNCDs risk factors in college students is still limited. In the city of Rio Branco, Acre state, college students show a high prevalence of overweight and obesity, a low intake of fruits and green vegetables and a high prevalence of sedentary behavior [12] [13]. Because of the importance of CNCDs nationally and the lack of relevant studies in the Brazilian Western Amazon, this investigation aims to analyze the prevalence of CNCDs and the associated lifestyle factors in college students in this region.

\section{Methods}

This was a cross-sectional study conducted in the second semester of 2010. The study population comprised approximately 4500 students enrolled in 34 undergraduate courses at the public university located in Rio Branco, Brazilian Western Amazon. Two-stage cluster sampling was used. In the selection of academics, the primary sampling units were the courses, and the secondary sampling units were the periods of the courses. The minimum sample size was determined using an expected prevalence of $50 \%$, a fixed accuracy for a sampling error of 0.05 , a confidence level of $95 \%$ and a design effect of 2 . For inclusion, students had to be registered and attending classes in an undergraduate program. This project was submitted to and approved by the Human Research Ethics Committee of Acre Federal University (Process no. 011544/2010-94).

A previously designed questionnaire was used to collect information on demographics, lifestyle, self-rated health status, anthropometrics and reported morbidities. Age was categorized in the following groups: 19 years or younger, between 20 and 29 years and 30 years or older. Self-reported health status was investigated using the question "How do you classify your health status?" The data were coded as either satisfactory (excellent or good) or unsatisfactory (fair or bad). Body mass index (BMI) was determined by dividing weight (in kilograms) by height (in meters) squared. Using World Health Organization recommendations [14], BMI was classified into three categories: eutrophic (less than $25 \mathrm{~kg} / \mathrm{m}^{2}$ ), overweight (between 25 and $30 \mathrm{~kg} / \mathrm{m}^{2}$ ) and obese (greater than $30 \mathrm{~kg} / \mathrm{m}^{2}$ ).

Smoking status was categorized as either current smoker (daily and occasional smoking) or non-smoker (individuals who had never smoked and former smokers). Consumption of alcoholic beverages in the 30 days prior to the study was measured by the procedure used by the Brazilian Health Ministry [10] in the study "Vigitel Brazil 2013: protective and risk factors for chronic diseases by telephone survey". Men who consumed 5 or more doses of alcoholic beverages met the criteria for intake. Five doses could be 5 cans of beer; 5 glasses of wine; or 5 doses of cachaça, whiskey or any other distilled spirits. For women, the minimum intake was 4 doses of alcoholic beverages. Participants who did not meet these criteria were categorized as "no intake".

The hours per week spent watching TV and using a computer were dichotomized as "less than or equal to 34.9 weekly hours" or "greater than or equal to 35 weekly hours". Data on the weekly frequency and duration of physical activity performed in the subjects' leisure time and walking as a means of locomotion were also collected. According to criteria by Haskell et al., [15] the variables measuring leisure-time physical activity and walking were categorized as either active or sedentary.

Weekly frequency of fruit and green vegetable intake was also measured, excluding potatoes, cassava and yams. The variables were combined and analyzed dichotomously: regular intake of fruit and green vegetables on 
5 or more days and irregular intake of fruit and green vegetables on 4 days of the week or fewer.

Presence of CNCDs was reported in the diagnostic report of a health care professional who evaluated the following parameters: dyslipidemia, high blood pressure, diabetes mellitus and cardiovascular events (infarction or stroke). The procedure for data collection on reported CNCDs was validated by Robinson et al. [16] and Martin et al. [17]. The college students were classified as having either one or more reported CNCDs or no reported CNCDs.

The data were entered using procedures specified by the EpiData software package. Statistical analyses were performed using Stata ${ }^{\mathrm{TM}}$ 10. The prevalence of CNCDs with 95\% confidence intervals (CI 95\%) was calculated for both total and stratified samples by gender and age. The prevalence ratios of the CNCDs for both crude prevalence and prevalence adjusted for age and gender were determined according to generalized linear models by using binomial distribution with a log link. The statistical power aposteriori was calculated using the GPower 3.1 program.

\section{Results}

Of the 874 students interviewed, $61.6 \%$ were female, and 38.4\% were male. Additionally, $26.2 \%$ were 19 years old or younger, $54.0 \%$ were between 20 and 29 , and $19.8 \%$ were 30 years old or older.

The overall prevalence of CNCDs was $15.6 \%$. Males showed a higher prevalence of CNCDs than females (18.1\% compared with 13.9\%). For both genders, CNCDs prevalence increased linearly with age. The highest prevalence rates were observed among participants age 30 years or older: $32.3 \%$ for males and $28.8 \%$ for females (Table 1).

The prevalence and prevalence ratio for CNCDs are shown in Table 2 according to the lifestyle factors, selfrated health status and BMI of college students in Rio Branco. After adjustment for gender and age, the variables measuring leisure-time physical activity, locomotion by walking, smoking, self-rated health status and BMI were identified as factors associated with CNCDs (Table 3). Students who were sedentary during leisure time and students who were sedentary in terms of locomotion by walking were found to have higher magnitudes of association with CNCDs: 1.67 (CI 95\%: 1.12 - 2.48) and 1.34 (CI 95\%: 1.00 - 1.79), respectively. Current smokers were 1.66 times as likely as non-smokers to have a CNCDs. Similarly, participants who reported unsatisfactory health status were 2.31(CI 95\%: 1.84 - 2.88) times as likely as those with satisfactory health status to have a CNCDs. A linear relation between the BMI and CNCDs was observed in the analysis of associated factors ( $\mathrm{p}$ for linear tendency $=0.000$ ). A posteriori, a prevalence ratio equal to or higher than 1.20 was estimated as statistically significant $(\mathrm{p}=0.05)$ to the statistical power of $80 \%$.

\section{Discussion}

The prevalence of CNCDs was 15.6\%, and male college students 30 years of age or older were more susceptible. In 2010, the overall CNCDs prevalence for Brazilians was 32.6\%, which is twice as high as the prevalence among college students in this study [6]. However, the majority of the college students were younger than 30 years old (81.2\%); therefore, they did not suffer from changes resulting from senescence, which would predispose them to the onset of CNCDs.

The procedure for using self-report to collect information on morbidities was validated [16] [17] to be used in health inquiries, and its simplicity and low cost are considered to be advantages. However, the quality of the information reported may vary by socioeconomic differences in accessing health care services and by sensitivity in perceiving one's health status. In this study, it was inferred that the college student's level of education reflected a minimum level of knowledge of their rights to access to health care services and a better understanding

Table 1. Prevalence of CNCDs by gender and age of college students from Rio Branco, Acre, Brazil, 2010.

\begin{tabular}{ccccc}
\hline & \multicolumn{2}{c}{ Males $(\mathbf{n}=\mathbf{3 3 6})$} & \multicolumn{2}{c}{ Females $(\mathbf{n}=\mathbf{5 3 8})$} \\
\cline { 2 - 5 } & $\%$ & CI 95\% & $\%$ & $(11.00 ; 16.87)$ \\
All & 18.1 & $(14.02 ; 22.28)$ & 13.9 & $(4.82 ; 14.48)$ \\
19 years or younger & 8.1 & $(1.83 ; 14.37)$ & 9.6 & $(7.77 ; 15.32)$ \\
Between 20 and 29 years & 15.5 & $(10.17 ; 21.03)$ & 11.5 & $(19.78 ; 37.94)$ \\
30 years or older & 32.3 & $(21.13 ; 43.57)$ & 28.8 & \\
\hline
\end{tabular}


Table 2. Prevalence and prevalence ratio of CNCDs by lifestyle factors, self-rated health status and body mass index of college students from Rio Branco, Acre, Brazil, 2010.

\begin{tabular}{|c|c|c|c|c|c|}
\hline & $\mathrm{n}$ & $\%$ & Crude PR & (CI 95\%) & $\mathrm{p}$ \\
\hline \multicolumn{6}{|l|}{ Leisure-time Physical Activity } \\
\hline Active & 325 & 11.6 & 1 & & \\
\hline Sedentary & 545 & 17.8 & 1.52 & $(1.10 ; 2.09)$ & 0.010 \\
\hline \multicolumn{6}{|l|}{ Locomotion by walking } \\
\hline Active & 179 & 12.2 & 1 & & \\
\hline Sedentary & 665 & 16.8 & 1.37 & $(1.03 ; 1.81)$ & 0.029 \\
\hline \multicolumn{6}{|l|}{ Hours of television watching } \\
\hline less than or equal to 34.9 weekly hours & 581 & 15.3 & 1 & & \\
\hline greater than or equal to 35 weekly hours & 265 & 16.2 & 1.05 & $(0.71 ; 1.57)$ & 0.776 \\
\hline \multicolumn{6}{|l|}{ Hours of computer use } \\
\hline less than or equal to 34.9 weekly hours & 541 & 15.7 & 1 & & \\
\hline greater than or equal to 35 weekly hours & 301 & 14.2 & 0.90 & $(0.59 ; 1.38)$ & 0.656 \\
\hline \multicolumn{6}{|l|}{ Smoking } \\
\hline Non-smoker & 821 & 14.9 & 1 & & \\
\hline Current smoker & 49 & 26.5 & 1.77 & $(1.12 ; 2.79)$ & 0.014 \\
\hline \multicolumn{6}{|l|}{ Alcohol intake in the last $\mathbf{3 0}$ days } \\
\hline No intake & 653 & 14.4 & 1 & & \\
\hline Intake & 219 & 19.1 & 1.33 & $(0.96 ; 1.83)$ & 0.079 \\
\hline \multicolumn{6}{|l|}{ Intake of fruit and green vegetables } \\
\hline $5 \mathrm{x}$ or more per week & 128 & 17.1 & 1 & & \\
\hline $4 \mathrm{x}$ or more per week & 735 & 15.5 & 0.90 & $(0.64 ; 1.26)$ & 0.555 \\
\hline \multicolumn{6}{|l|}{ Self-rated health status } \\
\hline Satisfactory & 671 & 12.0 & 1 & & \\
\hline Unsatisfactory & 203 & 27.0 & 2.24 & $(1.77 ; 2.84)$ & 0.000 \\
\hline \multicolumn{6}{|l|}{ Body Mass Index } \\
\hline Eutrophic & 586 & 11.0 & 1 & & \\
\hline Overweight & 169 & 21.8 & 1.97 & $(1.41 ; 2.76)$ & 0.000 \\
\hline Obese & 56 & 42.8 & 3.86 & $(2.61 ; 5.70)$ & 0.000 \\
\hline Tendency p & & & & & 0.000 \\
\hline
\end{tabular}

of the information provided by health care professionals.

This study has limitations. First, the cross-sectional design makes it impossible to analyze the temporality between the onset of CNCDs and behavioral change. Another limitation is survival bias. We considered that the college students affected by CNCDs were in the stage of the chronic disease that enables locomotion, understanding of class content and participation in university life. Because the college students affected by CNCDs required regular follow-up by health care professionals, it is inferred that memory bias is minimal.

It was found that self-rated health status is closely related to the physical symptoms [18] in subjects with more years of schooling [19] [20]. Also, cross-sectional studies have revealed the association between self-rated health with several morbidity [21] [22]. These findings support the association between unsatisfactory self-rated health status and CNCDs in this study by showing the negative impact of CNCDs on the well-being of college students.

This study found associations between the onset of CNCDs and sedentary habits in both leisure-time activity and locomotion by walking. These associations are consistent with well-known findings on the benefits of physical activity in the prevention of CNCDs [4] [23]. A classic cohort study on alumni from a North American uni- 
Table 3. Factors associated with CNCDs for college students from Rio Branco, Acre, Brazil, 2010.

\begin{tabular}{|c|c|c|c|}
\hline & Adjusted PR* & CI 95\% & $\mathrm{p}$ \\
\hline \multicolumn{4}{|c|}{ Leisure-time Physical Activity } \\
\hline Active & 1 & & \\
\hline Sedentary & 1.67 & $(1.12 ; 2.48)$ & 0.011 \\
\hline \multicolumn{4}{|c|}{ Locomotion by walking } \\
\hline Active & 1 & & \\
\hline Sedentary & 1.34 & $(1.00 ; 1.79)$ & 0.049 \\
\hline \multicolumn{4}{|l|}{ Smoking } \\
\hline Non-smoker & 1 & & \\
\hline Current smoker & 1.66 & $(1.07 ; 2.58)$ & 0.024 \\
\hline \multicolumn{4}{|c|}{ Self-Rated Health Status } \\
\hline Satisfactory & 1 & & \\
\hline Unsatisfactory & 2.31 & $(1.84 ; 2.88)$ & 0.000 \\
\hline \multicolumn{4}{|c|}{ Body Mass Index } \\
\hline Eutrophic & 1 & & \\
\hline Overweight & 1.67 & $(1.14 ; 2.46)$ & 0.008 \\
\hline Obese & 3.30 & $(2.18 ; 5.01)$ & 0.000 \\
\hline Tendency p & & & 0.000 \\
\hline
\end{tabular}

*Each variable adjusted for gender and age.

versity found that low physical activity increased the risk of CNCDs [24]. Many college students have double daily journey at work and studies at the university. As a result, there may be a decrease in the adhesion to leisure-time physical activityas a non-drug treatment for CNCDs.

In Brazil, the decline of some CDCNs occurred through tobacco control and improvement in health care [1]. Of the students in the study, 5.6\% were considered to be smokers, which supportsthe trendof a lowersmoking prevalencein the population from Rio Branco [25]. Other Brazilian studies with college students showed divergent results in smoking prevalence. For example, it was found that 7.2\% of students from Tocantins state [26] and 52.5\% students from Pernambuco state [11] were current smokers. Despite the low prevalence of smoking in this sample, the data confirmed a significant association between smoking and CNCDs [4]. Additionally, some participants continued smoking even after a CNCDs diagnosis by a health care professional, thus hindering treatment and exposing these individuals to CNCDs-related complications.

Some studies have demonstrated that the prevalence of CNCDs increases linearly with increasing BMI [27] [28]. A study involving nurses showed that the presence of obesity tripled the risk for the onset of coronary diseases, [21] which supports the finding that overweight and obese status were significantly associated with the onset of CNCDs in college students in Rio Branco. This association indicates a low adherence to the Brazilian [29] and international [30] recommendations for BMI reduction as a non-drug treatment for CNCDs.

\section{Conclusion}

Finally, this study showed a worrisome prevalence of CNCDs associated with sedentariness in terms of both leisure-time physical activities and locomotion by walking, smoking, unsatisfactory self-rated health status, overweight, and obesity. These findings are particularly important because the great majority of college students are young. Thus, we highlight the need for university-based programs aimed at the prevention of CNCDs and the promotion of healthy behaviors.

\section{References}

[1] Schmidt, M.I., Duncan, B.B., Azevedo e Silva, G., Menezes, A.M., Monteiro, C.A., Barreto, S.M., Chor, D. and Menezes, P.R. (2011) Chronic Non-Communicable Diseases in Brazil: Burden and Current Challenges. The Lancet, 377, 1949-1961. http://dx.doi.org/10.1016/S0140-6736(11)60135-9

[2] Boda, P.J. (2013) The Challenge of Combatting Non-Communicable Diseases in Trinidad: Access to Hospital Care. Health, 5, 12-18. http://dx.doi.org/10.4236/health.2013.511A2003 
[3] Park, J.M. (2014) Chronic Diseases, Health Status and Health Service Utilization among Koreans. Health, 6, 22862293. http://dx.doi.org/10.4236/health.2014.616263

[4] Ezzati, M. and Riboli, E. (2013) Behavioral and Dietary Risk Factors for Non-Communicable Diseases. New England Journal of Medicine, 369, 954-964. http://dx.doi.org/10.1056/NEJMra1203528

[5] Narayan, K.M., Ali, M.K. and Koplan, J.P. (2010) Global Noncommunicable Diseases—Where Worlds Meet. New England Journal of Medicine, 23, 1196-1198. http://dx.doi.org/10.1056/NEJMp1002024

[6] Barreto, S.M. and Figueiredo, R.C. (2009) Chronic Diseases, Self-Perceived Health Status and Health Risk Behaviors: Gender Differences. Revista de SaúdePública, 43, 38-47. http://dx.doi.org/10.1590/S0034-89102009000900006

[7] Ibanez-Gonzalez, D.L. (2014) Perspectives on Healthcare, Chronic Non-Communicable Disease, and in an Urban and Rural Setting. Global Health Action, 7. http://dx.doi.org/10.3402/gha.v7.25317

[8] Minh, H. and Tran, B. (2012) Assessing the Household Financial Burden Associated with the Chronic Non-Communicable Diseases in a Rural District of Vietnam. Global Health Action, 5. http://dx.doi.org/10.3402/gha.v5i0.18892

[9] Barros, M.B.A., Francisco, P.M.S.B, Zanchetta, L.M. and César, C.L.G. (2011) Trends in Social and Demographic Inequalities in the Prevalence of Chronic Diseases in Brazil. PNAD: 2003-2008. Ciência e SaúdeColetiva, 16, 3755-3768. http://dx.doi.org/10.1590/S1413-81232011001000012

[10] (2011) Brazilian Health Ministry. Vigitel Brazil 2010: Protective and Risk Factors for Chronic Diseases by Telephone Survey. MS, Brasília.

[11] França, C. and Colares, V. (2008) Comparative Study of Health Behavior among College Students at the Start and End of Their Courses. Revista de Saúde Pública, 42, 420-427.

[12] Ramalho, A.A., Dalamaria, T. and Souza, O.F. (2012) Regular Consumption of Fruits and Vegetables by University Students in Rio Branco, Acre State, Brazil: Prevalence and Associated Factors. Cadernos de Saúde Pública, 28, 14051413. http://dx.doi.org/10.1590/S0102-311X2012000700018

[13] Souza, O.F., Dalamaria, T. and Pinto, W.J. (2014) Socioeconomic Factors Associated with Overweight and Obesity in Young University Students. HealthMED, 8, 609-613.

[14] World Health Organization (1995) Physical Status: The Use and Interpretation of Anthropometric Indicators of Nutritional Status. WHO, Geneva.

[15] Haskell, W.L., Lee, I.M., Pate, R.R., Powell, K.E., Blair, S.N., Franklin, B.A., et al. (2007) Physical Activity and Public Health: Updated Recommendation for Adults from the American College of Sports Medicine and the American Heart Association. Circulation, 116, 1081-1093. http://dx.doi.org/10.1161/CIRCULATIONAHA.107.185649

[16] Robinson, J.R., Young, T.K., Roos, L.L. and Gelskey, D.E. (1997) Estimating the Burden of Disease. Comparing Administrative Data and Self-Reports. Medical Care, 35, 932-947.

[17] Martin, L.M., Leff, M., Calonge, N., Garrett, C. and Nelson, D.E. (2000) Validation of Self-Reported Chronic Conditions and Health Services in a Managed Care Population. American Journal of Preventive Medicine, 18, 215-218. http://dx.doi.org/10.1016/S0749-3797(99)00158-0

[18] Ratner, P.A., Johnson, J.L. and Jeffery, B. (1998) Examining Emotional, Physical, Social and Spiritual Health as Determinants of Self-Rated Health Status. American Journal of Health Promotion, 12, 275-282. http://dx.doi.org/10.4278/0890-1171-12.4.275

[19] Freire, L.M., Dalamaria, T., Cunha, M.A. and Souza, O.F. (2014) Self-Rated Health in University Students from Rio Branco in the Western Brazilian Amazon. Health, 6, 2245-2249. http://dx.doi.org/10.4236/health.2014.616260

[20] Zullig, K.J., Ward, R.M. and Horn, T. (2006) The Association between Perceived Spirituality, Religiosity, and Life Satisfaction: The Mediating Role of Self-Rated Health. Social Indicators Research, 79, 255-274. http://dx.doi.org/10.1007/s11205-005-4127-5

[21] Franks, P., Gold, M.R. and Fiscella, K. (2003) Sociodemographics, Self-Rated Health and Mortality in US. Social Science and Medicine, 56, 2505-2514. http://dx.doi.org/10.1016/S0277-9536(02)00281-2

[22] Peres, M.A., Masiero, A.V., Longo, G.Z., Rocha, G.C., Matos, I.B., Najnie, K., et al. (2010) Auto-avaliação da saúde em adultos no Sul do Brasil. Revista de Saúde Pública, 44, 901-911. http://dx.doi.org/10.1590/S0034-89102010000500016

[23] Lachat, C., Otchere, S., Roberfroid, D., Abdulai, A., Seret, F.M., Milesevic, J., Xuereb, G., Candeias, V. and Kolsteren, P. (2013) Diet and Physical Activity for the Prevention of Noncommunicable Diseases in Low- and Middle-Income Countries: A Systematic Policy Review. PLoS Medicine, 10, e1001465. http://dx.doi.org/10.1371/journal.pmed.1001465

[24] Paffenbarger, R.S., Wing, A.L., Hyde, R.T. and Jung, D.L. (1983) Physical Activity and Incidence of Hypertension in College Alumni. American Journal of Epidemiology, 117, 245-257.

[25] Martinelli, P.M., Lopes, C.M., Muniz, P.T. and Souza, O.F. (2014) Smoking in Adults in the Municipality of Rio 
Branco, Acre, Brazil: A Population-Based Study. Revista Brasileira de Epidemiologia, 17, 989-1000. http://dx.doi.org/10.1590/1809-4503201400040016

[26] Rodrigues, E.S.R., Cheik, N.C. and Mayer, A.F. (2008) Nível de atividade física e tabagismo em universitários. Revista de Saúde Pública, 42, 672-678. http://dx.doi.org/10.1590/S0034-89102008000400013

[27] Manson, J.E., Coldizt, G.A., Stampfer, M.J., Willett, W.C., Rosner, B., Monson, R.R., Speizer, F.E. and Hennekens, C.H. (1990) A Prospective Study of Obesity and Risk of Coronary Heart Disease in Women. New England Journal of Medicine, 322, 882-889. http://dx.doi.org/10.1056/NEJM199003293221303

[28] Gregg, E.W., Cheng, Y.J., Cadwell, B.L., Imperatore, G., Willians, D.E., Flegal, K.M., et al. (2005) Secular Trends in Cardiovascular Disease Risk Factors According to Body Mass Index in US Adults. JAMA, 293, 1868-1874. http://dx.doi.org/10.1001/jama.293.15.1868

[29] Sociedade Brasileira de Hipertensão (2010) Tratamento não-medicamentoso e abordagem multiprofissional. Revista Brasileira de Hipertensão, 17, 25-30.

[30] Krauss, R.M., Eckel, R.H., Howard, B., Appel, L.J., Daniels, S.R., Deckelbaum, R.J., et al. (2000) AHA Dietary Guidelines: Revision 2000: A Statement for Healthcare Professionals from the Nutrition Committee of the American Heart Association. Circulation, 102, 2284-2299. http://dx.doi.org/10.1161/01.CIR.102.18.2284 
Scientific Research Publishing (SCIRP) is one of the largest Open Access journal publishers. It is currently publishing more than 200 open access, online, peer-reviewed journals covering a wide range of academic disciplines. SCIRP serves the worldwide academic communities and contributes to the progress and application of science with its publication.

Other selected journals from SCIRP are listed as below. Submit your manuscript to us via either submit@scirp.org or Online Submission Portal.
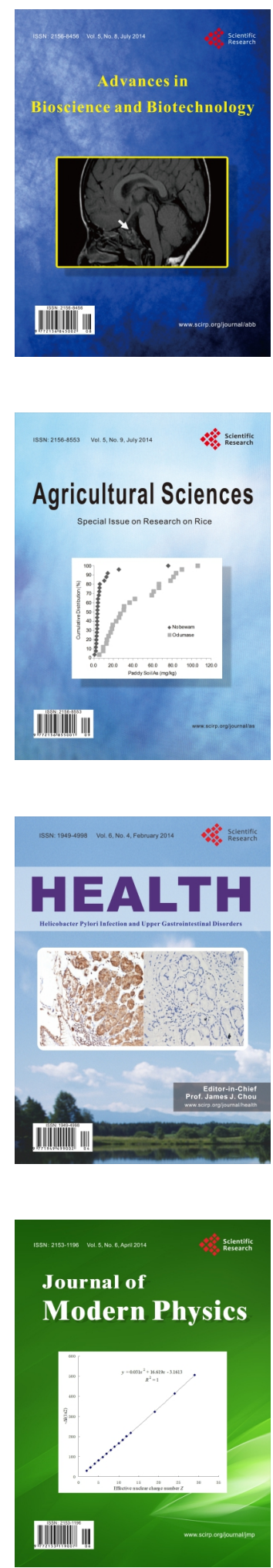
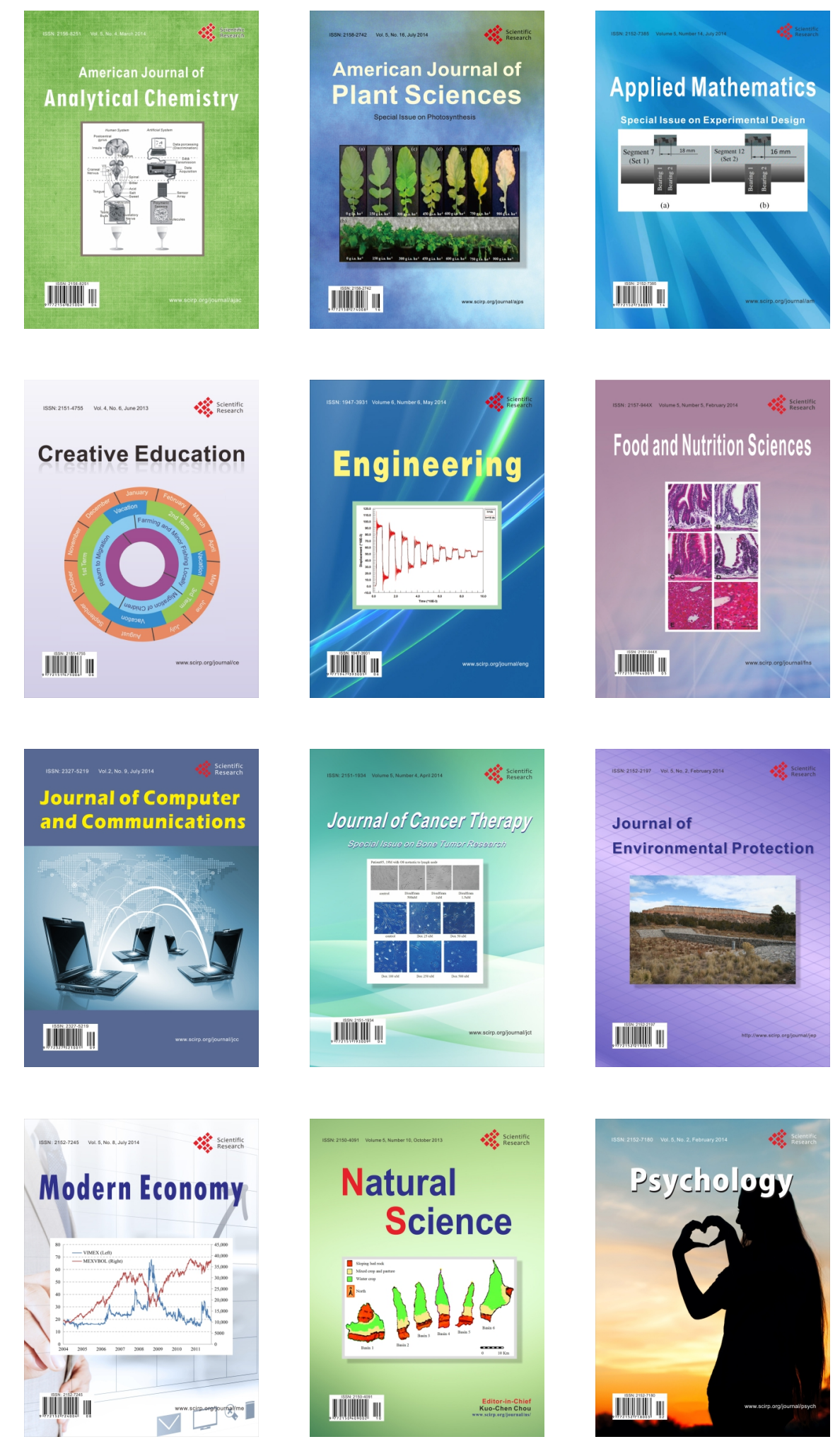